\title{
JOGO DE IMAGENS NA PÁGINA 2: ESTUDO PRELIMINAR DA LAVA JATO NOS EDITORIAIS DA GAZETA DO POVO ${ }^{12}$
}

\author{
Ester Pepes Athanásio ${ }^{3}$
}

\begin{abstract}
RESUMO
O artigo analisa, de maneira preliminar, a imagem pública da Operação Lava Jato nos editoriais da Gazeta do Povo, principal jornal do Paraná, a fim de identificar o discurso construído pelo principal jornal da cidade-sede da Operação, tendo como hipótese principal a ideia de que o jornal paranaense apoia e engrandece a Lava Jato e seus aliados, o que responde à sua linha editorial e também à expressividade que uma operação vinculada à área de atuação da Gazeta do Povo conquistou. Recorre-se à literatura sobre imagem pública política e teoria do jornalismo, já que o objeto é analisado a partir de material jornalístico. Ressaltam-se, portanto, as distinções dentre jornalismo informativo e opinativo, conferindo caráter privilegiado ao texto editorial - responsável pelo posicionamento oficial do veículo acerca da agenda pública. Tal texto contribui, enquanto ícone de visibilidade pública, para a construção da imagem de atores políticos ali expostos e é fundamental na formação da imagem pública do próprio veículo de comunicação. O corpus é composto de 10 editoriais de março a junho de 2016, submetidos à Análise do Discurso Francesa, por meio da qual foram identificadas as principais formações discursivas produzidas pelos editoriais jornalísticos. Conclui-se que há uma defesa convicta da Lava Jato, exibida como "implacável" trabalho de "limpeza ética" e "ruptura" política, o que confirma a hipótese de pesquisa apresentada.
\end{abstract}

Palavras-chave: Comunicação Política; Jornalismo; Editorial; Imagem pública; Lava Jato.

\begin{abstract}
The article analyses, in a preliminary way, the Lava Jato operation's public image in Gazeta do Povo editorials, the main newspaper of Paraná, in order to identify the speech built by the newspaper of the operation's home city. The main hypothesis main is that the newspaper supports and enhances the operation and its allies, which responds to its editorial line and the expressiveness won by the operation inside Gazeta do Povo's territory. It is used the literature on public political image and journalism theory, since the object is analyzed from journalistic material. Therefore, the distinctions between informative and opinionated journalism are highlighted, giving a privileged character to the editorial text - responsible for the official positioning of the vehicle on the public agenda. Such a text contributes, as an icon of public visibility, to the construction of the image of political actors exposed there and is fundamental in the formation of the public image of the communication vehicle itself. The corpus is composed of 10 editorials from March to June 2016, submitted to the French Discourse Analysis, through which the main discursive formations produced by journalistic editorials were identified. It is concluded that there is a convinced defense of the Lava Jato, shown as "relentless" work of "ethical cleansing" and political "rupture", which confirms the presented research hypothesis.
\end{abstract}

Keywords: Political Communication; Journalism; Editorial; Public Image; Lava Jato.

\section{RESUMEN}

Este artículo analiza, de manera preliminar, la imagen pública de la Operación Lava Jato en el editorial del Gazeta do Povo, el principal periódico de Paraná, con el fin de identificar el discurso construido por el principal periódico de la ciudad anfitriona de la operación. La hipótesis principal es la idea de que el periódico de Paraná apoya la operación y sus aliado, que responde a su línea editorial y también la expresión de que una operación vinculada a la zona de operaciones de la Gazeta do Povo. Se recurre a la literatura imagen pública política y la teoría del periodismo en adelante, ya que el objeto se analiza a partir de material periodístico. Destacar, por lo tanto, las diferencias entre el periodismo informativo y obstinado, dando carácter privilegiado al texto editorial - responsable de la posición oficial del vehículo en la agenda pública. Este texto contribuye, como un icono de visibilidad pública para la construcción de la imagen de los actores políticos no expuestas y es fundamental en la formación de la imagen pública del propio vehículo de comunicación. El corpus consiste en editorial del 10 de marzo a junio de 2016, sometido al análisis del discurso francés, a través del cual las principales formaciones discursivas producidas por editoriales de los periódicos han sido identificados. Llegamos a la conclusión de que hay una defensa

\footnotetext{
${ }^{1}$ Enviado: 01/04/2017

Aceito: 16/06/2017

${ }^{2}$ DOI: $10.5380 /$ recp.v8i1.51570

${ }^{3}$ Jornalista e Mestranda em Comunicação e Política pela Universidade Federal do Paraná (UFPR). Participa dos grupos de pesquisa Comunicação e Democracia (DEMOCOM) e Comunicação, Política e Tecnologia (PONTE).
} 
ATHANÁSIO, E.P. Jogo de imagens na página 2: estudo preliminar da Lava Jato nos editoriais da Gazeta do Povo

convencida de Lava Jato, exibida como trabajo de "limpieza étnica" "implacable" y "ruptura" de la política, lo que confirma la hipótesis de la investigación presentada.

Palavras claves: La comunicación política; Periodismo; Editorial; Imagen Pública; Lava Jato.

\section{INTRODUÇÃ̃O}

A linha de chegada da corrida eleitoral de 2014, polarizada entre Dilma Roussef (PT) e Aécio Neves (PSDB), inaugurou um período turbulento na política brasileira. Ao vencer a eleição presidencial mais apertada e polarizada da história, com apenas 3,28 \% de vantagem nas urnas $(3,4 \text { milhões de votos })^{4}$ e com o início de um período de instabilidade econômica, Dilma Rousseff abriu o segundo mandato com uma soma de baixas que a conduziram a sucessivas perdas na aprovação - processo que vinha se agravando desde junho de 2013, tendo conquistado algum fôlego durante a acirrada campanha. Se em março de 2013 a petista exibia os surpreendentes $65 \%$ de aprovação, segundo o DataFolha, um ano depois, a taxa chegou a 36\%. O ano de 2015 começou difícil (23\%) e terminou ainda pior (8\%), com taxas de rejeição que chegavam a $71 \%$, superando o pior momento do ex-presidente Fernando Collor $(65 \%)^{5}$, que esteve na Presidência da República entre 1990 e 1992. A entrada em 2016 representou o agravo da crise política.

Sem desprezar fatores econômicos e de ordem administrativa, pode-se afirmar que a Operação Lava Jato (LJ), que investiga um esquema bilionário de corrupção na Petrobrás desde março de 2014 e atingiu a classe política em março de 2015, exerceu forte influência nos desdobramentos do cenário político dos últimos dois anos (ALVRITZER, 2016). A maior investigação anticorrupção já desempenhada no Brasil encontrou conformação na população que reivindicava o fim da impunidade; e a firmeza atribuída ao juiz federal Sérgio Moro ${ }^{6}$ apareceu com catalisador do processo.

Em 2016, as tentativas de impeachment apresentadas na Câmara dos Deputados ganharam corpo a partir do rompimento do presidente da casa, Eduardo Cunha (PMDB), com o governo petista. Embora as justificativas não tivessem relação com a Lava Jato, o desgaste que o governo sofreu por abrigar uma série de nomes investigados reforçou a iniciativa de

\footnotetext{
4 Dados disponíveis em: http://eleicoes.uol.com.br/2014/noticias/2014/10/26/dilma-cresce-na-reta-final-ereeleita-e-emplaca-quarto-mandato-do-pt.htm, acesso em 21 de julho de 2016.

${ }^{5}$ Acesso em 21 de julho de 2016. Dados disponíveis em:

http://datafolha.folha.uol.com.br/opiniaopublica/avaliacaodegoverno/presidente/dilma/indice-1.shtml

${ }^{6}$ Juiz da $13^{\text {a }}$ Vara Federal Criminal de Curitiba, Sérgio Moro ganhou visibilidade pela atuação no julgamento da Operação Lava Jato. Sua trajetória passa por casos expressivos de combate à corrupção. Atuou na Operação Banestado, em 2010 (escândalo do Banco do Estado do Paraná na década de 1990) e foi juiz instrutor do Supremo Tribunal Federal (STF) durante julgamento do caso Mensalão (caso mais expressivo durante governo Lula, PT).
} 
afastar Dilma. Não é à toa que as manifestações populares pró-impeachment, lideradas pelo Movimento Brasil Livre (MBL), não raramente apresentavam ícones da operação, tais como bonecos infláveis e cartazes de apoio a Moro ${ }^{7}$. Em março, a condução coercitiva do expresidente Lula seguida de uma nomeação para o Ministério da Casa Civil (supostamente a fim de protegê-lo do julgamento na "República de Curitiba") ${ }^{8}$ e do vazamento de uma conversa entre ele e Dilma, levou a credibilidade do quarto mandato petista consecutivo a níveis desastrosos, até que, no dia 17 de abril de 2016, os deputados federais admitiram o afastamento de Dilma (367 x 137) e em 12 de maio o pedido foi confirmado pelo Senado (55 x 22). Os registros das discussões e votações evidenciam a pressão que a Operação Lava Jato exerceu, sendo usada como um dos principais argumentos daqueles que foram favoráveis à interrupção do mandato.

Estudos da interface entre Comunicação e Política apontam para o papel mediador e formador da Opinião Pública que é desempenhado pelos meios de comunicação de massa e, em especial, pelo jornalismo (GOMES, 2004; RINKE, 2015; MAIA, 2008). A formação da imagem da Operação Lava Jato é uma construção elaborada por diversos fatores e a cobertura noticiosa ocupa uma centralidade conferida pela credibilidade da prática jornalística que estabelece um contrato de veracidade com seus consumidores. Para este artigo interessa, em especial, a imagem pública da Operação Lava Jato construída nos editoriais da Gazeta do Povo ${ }^{9}$, o principal jornal do Paraná - onde está instalada a Força-Tarefa da Lava Jato.

\section{POLÍTICA E IMAGEM PÚBLICA}

A Lava Jato investiga empreiteiras, doleiros e empresas estatais, mas causou maior impacto no cenário público ao revelar a participação de atores políticos importantes da política brasileira. Ao colocar em xeque a idoneidade dessas autoridades, a imagem pública dos envolvidos é julgada, exposta e alterada de acordo com o jogo de imagens proposto pela comunicação de massa. Os políticos são obrigados a lidar com um efeito negativo da esfera de visibilidade pública. Por "jogo de imagens" compreende-se a disputa, entre diferentes atores

\footnotetext{
${ }^{7}$ Imagem de Sérgio Moro foi constantemente associada às manifestações pró-impeachment, a exemplo desta reportagem que trata da manifestação de 13 de março de 2016: http://politica.estadao.com.br/blogs/faustomacedo/na-terra-da-lava-jato-200-mil-apoiam-juiz-sergio-moro-em-ato-pro-impeachment/

${ }^{8}$ Reportagem jornalística sobre fato pode ser lida em: http://www1.folha.uol.com.br/poder/2016/03/1750752dilma-agiu-para-tentar-evitar-a-prisao-de-lula-diz-pf.shtml

${ }^{9}$ Embora tenha anunciado, no início de 2017, o fim da circulação da edição imprensa, a Gazeta do Povo é o $5^{\circ}$ Jornal mais acessado do Brasil. Segundo a Associação Nacional de Jornal, em 2015 a tiragem do jornal foi de 36.341 exemplares diários. Integra um dos maiores grupos de comunicação do país, o GRPCOM, que reúne, além de jornais, emissoras de TV e rádio, incluindo a RPC, filiada da Rede Globo no Paraná.
} 
ATHANÁSIO, E.P. Jogo de imagens na página 2: estudo preliminar da Lava Jato nos editoriais da Gazeta do Povo

sociais, pela construção de imagens positivas frente à Opinião Pública; e o Jornalismo detém papel fundamental nesta dinâmica, sendo agente formador de imagens de terceiros e dele próprio, legitimando determinadas posições, personalidades e instituições e rechaçando outras. Assim, atua não apenas como mediador entre sociedade e campo político, mas também como próprio ator político, interferindo na arena de discussões e, quiçá, nas decisões de ordem pública, seja por influenciar as conviçcões individuais do público ou provocar a decisão dos próprios agentes políticos.

A arena midiática é um espaço de lutas constantes em torno da construção de uma imagem pública positiva. Essa articulação com as organizações midiáticas é acionada com intuito de engrandecer um grupo político e desqualificar o adversário e, durante as crises políticas e escândalos, os adversários podem facilmente desconstruir a imagem do opositor e se reposicionar favoravelmente perante a Opinião Pública. Construção e desconstrução de imagens são processos simultâneos e constantes (WEBER, 2004).

Essa disputa de imagem é constituída da participação ativa de atores políticos, embora as representações não estejam totalmente sob seu controle. Na política de imagem, a administração da imagem pública está sujeita à ação de aliados, adversários e a circunstâncias próprias do jogo político; é apoiada e construída sobre mecanismos de enunciados linguísticos (GOMES, 2004).

Ao tratar das transformações sofridas pela política na chamada "era da comunicação de massa”, Wilson Gomes (2004) afirma que a política de imagem existe desde a antiguidade, mas devido à centralidade da esfera de visibilidade das sociedades contemporâneas, há especificidades próprias da era da comunicação de massa. Neste contexto, a imagem pública raramente pode ser construída por experiência sensorial direta e, portanto, é mediada pelos meios de comunicação de massa. Princípios, lógicas e interesses das instituições de comunicação selecionam, estruturam e disseminam imagens.

Gomes (2004) tem o cuidado de esclarecer a metáfora da imagem para que não seja reduzida ao sentido visual. A imagem pública não tem relação com imagem plástica. É uma analogia de representação que define um fato cognitivo. Imagem pública é representação, todavia, se distingue do icônico e imagético. Por essa razão, admitem-se imagens de coisas que não possuem representação visual, como é o caso da Operação Lava Jato, que sequer possui sede própria. Sua imagem está associada a pessoas e instituições, mas não possui uma imagem física própria, o que não descarta a existência de uma imagem pública própria. As imagens se 
constroem de ações e discursos e não de representações visuais. Os elementos visuais surgem para complementar ou reforçar uma ideia.

Imagem pública é um conjunto de noções, conceitos e informações sobre algo compartilhado por uma coletividade. É uma concepção caracterizadora, um reconhecimento que é atribuição. É a projeção de uma identidade (GOMES, 2004), o que é percebido sobre algo (GALICIA, 2010). O conceito de imagem pública equivale à reputação, fama e nome. Imagem é aquilo que algo parece ser; "o intermediário cognitivo entre nós e aquilo que se quer conhecer" (GOMES, 2004).

Os atores políticos promovem a fabricação de imagens em torno da imagem desejada (WEBER, 2004): planejam a projeção de uma imagem ideal, mas os resultados são pouco controláveis, pois do público resulta a imagem percebida. O que medeia esse processo são os meios de comunicação.

Quem cria e forma a imagem pública? Um conjunto de técnicas e de gerenciadores de emissão de mensagens sob controle do campo político dão início ao fluxo, entretanto, a subjetividade humana domina o processo: a imagem pública começa a existir apenas na recepção, embora programada na emissão. De acordo com Gomes (2004), há três fases: (1) sob controle dos agentes políticos e seus "técnicos da criação e gerenciamento da emissão de mensagens" (no caso da Lava Jato pode-se supor que integrem essa fase o juiz, a Justiça Federal, Polícia Federal, Ministério Público Federal); (2) o campo da comunicação, como detentor da esfera de visibilidade e, em especial, o jornalismo, organiza as informações que já não estão sob domínio de atores políticos; (3) informações são equacionadas pelo público (a recepção) e os pré-conceitos de decodificação (quadros hermenêuticos) individuais.

Weber (2004) e Galicia (2010) preveem um fluxo de informações com fases semelhantes, embora Galícia se concentre nos estudos de comunicação eleitoral. Weber ressalta o afastamento que a imagem percebida terá da imagem desejada. Ou seja, por mais que esteja ancorada em um objeto real, sua assimilação, ao longo do processo, tende a ser desprendida. $\mathrm{O}$ espectador é o ator principal.

A imagem não é uma invenção. Apesar de conter um esforço dos agentes políticos em salientar fatores positivos e minimizar os negativos, é uma representação do real. Logo, está ancorada em recortes da realidade e não pode ser drasticamente incoerente sob pena de descrédito. As características reais da personalidade ou instituição não podem ser desconectadas de sua representação: é preciso, ao menos, parecer ser.

Confere-se atenção à imagem da Operação, admitindo-se o desafio de estudar a imagem pública deste objeto que não é personalidade, nem instituição, mas reúne um conjunto 
ATHANÁSIO, E.P. Jogo de imagens na página 2: estudo preliminar da Lava Jato nos editoriais da Gazeta do Povo

de personalidades e instituições. A imagem da Lava Jato está associada à imagem de outros atores e deles não pode ser dissociada. A credibilidade da operação conversa com a confiança atribuída a instituições e personalidades centrais.

O jornalismo depende desses atores para obter informações e, assim, se legitimar em seu papel social, e as instituições políticas recorrem à esfera de visibilidade pública sob controle do campo da comunicação e, em especial, da imprensa e do jornalismo a fim de configurarem uma imagem pública positiva. É a publicização de suas ações que os faz conhecidos e reconhecidos e configura determinadas representações. A comunicação medeia os demais campos e veicula representações.

\subsection{Notícia: Espaço de disputa por visibilidade pública}

Ao jornalismo se atribui os papeis de fiscalizador (cão de guarda e quarto poder); defensor do bem público, peça fundamental na estruturação da esfera pública (MAIA, 2008) e formador da Opinião Pública. O estudo do agendamento (ou agenda setting) corrobora ao defender que os meios de comunicação pautam a agenda pública estabelecendo os assuntos prioritários e que merecem atenção no debate (McCOMBS e SHAW, 1972) e a noção de enquadramento ou framing aprofunda a ideia ao defender que o jornalismo delimita perspectivas específicas de análise das temáticas agendadas (ENTMAN, 1993). São abordagens que colaboram para a compreensão da atuação do jornalismo na esfera pública, como mediador e formador da Opinião Pública (GOMES, 2008).

$\mathrm{O}$ crédito que o jornalismo detém como fonte de veracidade - o que, em partes, o distingue de outros produtos midiáticos (WEBER, 2004), fundamenta a confiança da população na tomada de decisões. Isso fica claro nas consultas públicas e eleições, embora seja primordial na pressão exercida sobre o campo político também durante o mandato. A imprensa tem a capacidade de organizar e de dar visibilidade às demandas de interesse público, (in)formar sobre ações dos agentes políticos e ofertar perspectivas de análise, contribuindo para configuração da imagem pública de atores e instituições.

A credibilidade para tanto remete às Teorias do Jornalismo, que consolidaram, ao longo do século XX, junto do desenvolvimento da comunicação de massa e a partir da influência do positivismo e do cientificismo, a prática da reportagem como uma iniciativa neutra, imparcial e objetiva, que reduziria toda subjetividade em prol do reflexo da realidade (Teoria do Espelho), agindo de forma desinteressada, ou melhor, assumindo o interesse público 
como único. A partir da visão idealista, o jornalismo se legitimou como fonte de veracidade, apto a orientar as massas sem, contudo, estar sujeito a algum interesse particular (BARROS FILHO, 1995).

Deste mesmo momento histórico, situado no contexto ocidental de influência americana, surgem as distinções entre a imprensa informativa (pautada nos critérios de objetividade) e a imprensa opinativa. Os jornais passam a delimitar os espaços de opinião e classificar as produções: reportagens, matérias, entrevistas e notas compõem o quadro noticioso; a opinião está pretensamente restrita a colunas, comentários, artigos, crônicas e editoriais, em que a opinião é caracterizadora do gênero textual. Já na Europa, o jornalismo partidário exerceu maior influência e configurou um contrato distinto com os leitores. A identidade dos jornais foi baseada no posicionamento político e a separação entre fato e opinião seria paradoxal (SCHUDSON, 2001, apud BIROLI; MIGUEL, 2012).

Ao longo das últimas décadas, a exigência da objetividade foi colocada em xeque e reorientada para compreensões variadas, embora seja ponto pacífico a ideia de que constitui um ideal impraticável: ora é defendida como norte utópico, ora é recriminada como prática indesejável (BARROS FILHO, 1995) ou ainda classificada como um ritual estratégico da profissão (TUCHMAN, 1972). A Teoria do Espelho sofreu concorrências de outras sistematizações, que se afastaram da visão de centralidade do repórter e passaram a considerar outros fatores para dar conta da produção noticiosa, como a Teoria Organizacional, que se volta para a empresa jornalística, buscando compreender a notícia a partir das relações que se dão em seu contexto imediato de produção: as redações jornalísticas (BREED, 1955). Já a Teoria Construcionista substituiu a ideia de espelho do real e resignificou a notícia como peça da construção da realidade (TUCHMAN, 1973). Embora o campo teórico tenha se dedicado a desmistificar o rigor da objetividade, as exigências em torno deste princípio ético constitui uma herança perpetuada em diferentes esferas e a ausência de zelo por parte dos veículos de comunicação torna-se, não raramente, objeto de críticas severas (EILDERS, 1999). Os espaços de opinião e notícia estão claramente delimitados, tanto na diagramação quanto nos processos, em uma constante tentativa de se validar a credibilidade e compromisso democrático das organizações midiáticas.

Não se pode descartar o papel do produto jornalístico na conformação de imagens públicas, tampouco se pode atribuir poder exclusivo a este. A imagem pública de algo ou alguém é formada a partir de uma série de fatores e sua mensuração é de difícil apreensão embora os institutos de sondagem acreditem deter essa condição analítica. Neste artigo, estudamos a imagem pública da Operação Lava Jato traduzida nos editoriais da Gazeta do Povo 
ATHANÁSIO, E.P. Jogo de imagens na página 2: estudo preliminar da Lava Jato nos editoriais da Gazeta do Povo

entre março e junho de 2016, o que não significa assumir que tais resultados reflitam a imagem pública que a Operação detém no todo - já que neste momento analisa-se um recorte temporal particular e apenas dos editoriais de um único jornal. É um recorte específico, que procura contribuir com o conhecimento do que um jornal regional, geograficamente próximo das atividades da Operação Lava Jato e interessado em seus processos, produziu em suas páginas de opinião institucionais, isto é, nos textos editoriais, buscando apreender, a opinião da empresa de comunicação a respeito desse fato político e de que forma contribui para a formação de sua imagem pública nas páginas opinativas.

A seguir, debatem-se as especificidades do texto editorial.

\subsubsection{Editorial: A voz do jornal na esfera pública}

No conjunto opinativo, os editoriais assumem relevância e apresentam especificidades pouco exploradas pela pesquisa (MARQUES, MONT'ALVERNE, 2013). É um ambiente único, reservado para o posicionamento oficial do veículo, frequentemente ocupado com discussões sobre temáticas consideradas polêmicas e de maior destaque (MARQUES DE MELO, 2003). Isto é, há uma hierarquia que define os temas "dignos de um editorial".

O consumo de produtos jornalísticos também representa, em alguma medida, a absorção de opiniões já consolidadas. O jornal legitima vozes e opiniões, chancelando aquelas autorizadas a se posicionar publicamente, seja pelo cargo público ocupado ou pela especialidade no tema em debate. Nos editoriais, encontra-se a opinião explícita e oficial do jornal. É um ambiente de franqueza em que o contrato entre leitor e jornal é alterado. Já não se espera consumir a "realidade dos fatos isenta de posição", tampouco se exige um equilíbrio de versões. É um espaço para se consumir opinião e saber "o que pensa o jornal".

É necessário ponderar aspectos corporativos dos jornais. Cabe avaliar que essas empresas possuem interesses próprios, sejam eles políticos, ideológicos, sociais, econômicos ou religiosos, que não podem ser ignorados. Como empresa, o jornal lança mão do texto editorial e assume lugar de fala autorizado e socialmente legitimado na arena de discussões, se configurando como peça fundamental de articulação na esfera pública. Isso não significa dizer que os espaços noticiosos não constituam matéria de análise do posicionamento dos veículos e da imagem que constroem de si mesmos, mas é preciso ressaltar que o editorial, dentro dos procedimentos de produção jornalística, exerce uma função singular. É voz ativa do jornal enquanto instituição. 
Há um "elemento local” na cobertura noticiosa dos veículos, que priorizam eventos dentro da sua regionalidade e, embora a abrangência da Lava Jato não esteja reduzida ao âmbito estadual, a instalação da Força-Tarefa no Paraná e a atuação expressiva do juiz Sérgio Moro supõe uma atenção especial dos veículos locais, o que justifica a escolha do jornal Gazeta do Povo neste artigo.

\section{RESULTADOS E ANÁLISE DOS DADOS}

Compõem o corpus da pesquisa 10 (dez) editoriais do Jornal Gazeta do Povo (GP), publicados entre os meses de março e junho de 2016, período que inclui as semanas que antecederam a mudança de governo, os dias de transição e o primeiro mês de exercício do governo interino. O jornal publica um editorial por dia e foram selecionados para esse estudo apenas aqueles que apresentavam a Lava Jato como tema central, o que implica na exclusão de textos que tenham mencionado a Lava Jato de modo secundário. A íntegra dos textos analisados é fornecida mediante solicitação à autora.

O recurso utilizado é a Análise do Discurso (AD), que propõe uma reflexão sobre as condições de produção do texto, buscando compreender a formação social de sentido. Aqui, considera-se a origem francesa da $\mathrm{AD}$ e as teorias do jornalismo como ponto de partida para compreensão do texto jornalístico como discurso (BENETTI, 2008).

A opção pela Análise do Discurso Francesa se dá pela compreensão de que tal proposta teórico-metodológica "ultrapassa o status de simples técnica de análise para compor um campo do conhecimento" e analisa as condições de produção do texto em seu contexto históricoideológico, como ambicionam os objetivos de investigação futura, da qual este artigo representa etapa embrionária. A AD é uma proposta crítica de busca de sentidos implícitos, em que palavras são pistas de um contexto maior. “(...) a análise do discurso considera que a situação está atestada no texto e busca mais a compreensão do processo produtivo do discurso do que a interpretação do texto como um fim em si mesmo" (CAPPELLE, MELO, GONÇALVES, 2003). É uma perspectiva que ultrapassa a contribuição meramente descritiva, portanto (CARVALHO, 2013). Logo, compreende-se que a Análise do Discurso contribui não apenas para a interpretação do que está explícito nos textos (considerando, sobretudo, que o editorial consiste em texto de opinião, caracterizado por expor visões de forma evidente), mas também na busca por elementos que não estão explicitados, com "critérios para o estudo capazes de revelar aquilo que não é dito". Realça-se, então, o objetivo de "saber identificar as intenções do 
ATHANÁSIO, E.P. Jogo de imagens na página 2: estudo preliminar da Lava Jato nos editoriais da Gazeta do Povo

autor, de considerar os fatores que determinam a influência sobre a forma como o conteúdo é construído e que definem a versão final que será lida” (CARVALHO, 2013, p. 8).

A contribuição de Bennetti (2008) está em somar à perspectiva abordagens teóricas próprias do jornalismo, compreendendo que o texto jornalístico possui particularidades, uma lógica distinta que não pode ser desprezada; logo, a incorporação do conhecimento sobre Jornalismo auxilia na interpretação do processo de produção do discurso jornalístico, os atores envolvidos e as relações de poder, o que é fundamental para a AD. Carvalho (2013, p. 8) compartilha dessa visão, considerando que para o uso adequado da metodologia de origem linguística "é fundamental compreender que sua aplicabilidade ao jornalismo deve considerar determinadas especificidades e que neste sentido há a necessidade de adequar sua proposta para a realidade da construção da notícia".

Para análise dos documentos coletados foi adotada como estratégia principal a identificação das formações discursivas (também denominadas sentidos nucleares) mais recorrentes nos textos editoriais. Essa etapa observou as principais formações discursivas, isto é "os elementos do texto que de algum modo propõe uma forma de interpretar os fatos" (CARVALHO, 2013, p. 22). Essas formações discursivas, ou núcleos de sentido, são assimiladas ao longo dos textos a partir da percepção de um "movimento de paráfrase, isto é, a repetição e o reforço do mesmo sentido, através das sequências discursivas ao longo do(s) texto(s)" (PINHEIRO, 2013).

Como etapa metodológica, os trechos recortados para análise e utilizados no relato da pesquisa são chamados de sequências discursivas (SDs), que correspondem aos fragmentos do texto que reforçam e exemplificam a adesão à determinada formação discursiva FD. Para identificação das formações discursivas o corpus é lido integralmente e analisado. Os posicionamentos significativos que se repetem com frequência foram recortados e classificados como formações discursivas. Esse procedimento é parte das recomendações de Benetti (2008) sobre Análise do Discurso em Jornalismo e foi aplicado por Pinheiro (2013) no estudo sobre editoriais de O Estado de São Paulo.

$\mathrm{Na}$ primeira etapa, foram lidos todos os textos e identificadas as principais questões enfatizadas pelo jornal, o que nos permite apontar formações discursivas (FDs) mais recorrentes, que reforçam a posição da empresa sobre o tema. As SDs podem se repetir e ser utilizadas em mais de uma FD, logo, não são categorizações exclusivas e indicam, justamente, a força da SD. Foram identificadas as seguintes FDs: (1) a ofensiva política contra a Lava Jato; (2) PT, o inimigo número 1; (3) A operação legítima e defensável; (4) A competência de Sérgio 
Moro; (5) Temer não deve temer, mas ser firme e (6) A população deve agir e reagir. A sequência apresentada reflete o grau de recorrência de cada FD. Cada FD reúne Sequências Discursivas (SDs) relativas à abordagem em questão.

\section{FD1: A ofensiva política contra a Lava Jato}

Segundo a Gazeta do Povo (GP), há uma série de tentativas da classe política para conter o avanço da Lava Jato; o PT e o legislativo aparecem como protagonistas desse processo. Assim, cria-se a imagem negativa dos atores políticos, de maneira geral, mas de forma mais concentrada no PT e no legislativo, transmitindo a ideia de que petistas e determinados parlamentares buscam interromper a Operação.

Tabela 1 - FD1

\begin{tabular}{|c|c|}
\hline Sequência Discursiva & Editorial \\
\hline $\begin{array}{l}\text { SD1: "Dilma teria tentado interferir no andamento da Lava Jato em } \\
\text { pelo menos três ocasiões" }\end{array}$ & $\begin{array}{l}\text { E01: Acusações } \\
\text { explosivas }\end{array}$ \\
\hline $\begin{array}{l}\text { SD 2: "desmoralizar o juiz federal Sergio Moro já era uma } \\
\text { estratégia dos investigados da Lava Jato havia um bom tempo" }\end{array}$ & $\begin{array}{l}\text { E02: A lei está do lado } \\
\text { de Moro }\end{array}$ \\
\hline $\begin{array}{l}\text { SD3: "O novo ministro da Justiça ataca as delações premiadas da } \\
\text { Lava Jato e ameaça trocar toda uma equipe caso suspeite de } \\
\text { vazamentos" }\end{array}$ & \multirow{4}{*}{$\begin{array}{l}\text { E03: Aragão parte para } \\
\text { o ataque }\end{array}$} \\
\hline $\begin{array}{l}\text { SD4: “Qual seria a melhor estratégia para um governo acuado pela } \\
\text { Operação Lava Jato e interessado em jogar água na fervura das } \\
\text { investigações que chegaram ao centro do poder petista?" }\end{array}$ & \\
\hline $\begin{array}{l}\text { SD5: "graças à pressão do ex-presidente Lula, para quem era } \\
\text { obrigação de Cardozo domesticar a Polícia Federal para que a Lava } \\
\text { Jato não incomodasse o chefão petista e seus familiares" }\end{array}$ & \\
\hline $\begin{array}{l}\text { SD6: "Se Aragão estiver realmente disposto a minar a Lava Jato, a } \\
\text { sociedade precisa reagir com a mesma força que demonstrou após a } \\
\text { tentativa de levar Lula para o ministério" }\end{array}$ & \\
\hline $\begin{array}{l}\text { SD7: "Daí advêm os sinais, cada vez mais frequentes, de que há o } \\
\text { ânimo, ainda que inconfessado e subterrâneo, de um grupo de } \\
\text { peemedebistas investigados de tentar esvaziar a Operação" }\end{array}$ & $\begin{array}{l}\text { E05: Proteção } \\
\text { incondicional à Lava } \\
\text { Jato }\end{array}$ \\
\hline $\begin{array}{l}\text { SD8: "todas as tentativas de interferência saíram fracassadas e } \\
\text { com um alto preço pago por boa parte dos envolvidos" }\end{array}$ & \multirow{3}{*}{$\begin{array}{l}\text { E06: Contra a } \\
\text { corrupção }\end{array}$} \\
\hline $\begin{array}{l}\text { SD9: "Se algum risco existe, ele está não no âmbito do Poder } \\
\text { Executivo, mas no Poder Legislativo" }\end{array}$ & \\
\hline $\begin{array}{l}\text { SD10: "Não por acaso ameaças semelhantes começam a emergir das } \\
\text { sombras do Congresso Nacional. É emblemática a divulgação nesta } \\
\text { semana da conversa gravada pelo ex-diretor da Transpetro, Sérgio }\end{array}$ & \\
\hline
\end{tabular}




\begin{tabular}{|c|c|}
\hline $\begin{array}{l}\text { Machado, em que o presidente do Senado, Renan Calheiros (PMDB- } \\
\text { AL), afirma apoiar uma mudança na } \\
\text { lei que trata da delação premiada, com o objetivo de impedir que } \\
\text { uma pessoa presa possa se tornar um delator. É exatamente esse o tipo } \\
\text { de medida que não vai contribuir para o florescimento de um ambiente } \\
\text { menos corrupto no Brasil" }\end{array}$ & \\
\hline $\begin{array}{l}\text { SD11: "Ainda que o pedido de prisão de Renan, Jucá, Sarney e } \\
\text { Cunha não prospere, ele alerta os brasileiros sobre as inúmeras } \\
\text { tentativas de perpetuar a corrupção" }\end{array}$ & \multirow{4}{*}{$\begin{array}{l}\text { E07: A trama contra a } \\
\quad \text { Lava Jato }\end{array}$} \\
\hline $\begin{array}{l}\text { SD12: "Mas o episódio serve de alerta a toda a sociedade brasileira } \\
\text { sobre as inúmeras tentativas de perpetuar a corrupção nos altos } \\
\text { escalões do poder federal" }\end{array}$ & \\
\hline $\begin{array}{l}\text { SD13: "O primeiro front consiste em acabar com a Lava Jato } \\
\text { propriamente dita, ou pelo menos burlá-la onde for possível. Tais } \\
\text { movimentações vêm desde o governo Dilma" }\end{array}$ & \\
\hline $\begin{array}{l}\text { SD14: "Seria ingenuidade imaginar que a queda de Dilma } \\
\text { interrompesse as tramoias, já que o PMDB é praticamente um } \\
\text { coprotagonista do petrolão. Mas as gravações de Sérgio Machado } \\
\text { mostram que a intenção não era apenas blindar os atuais } \\
\text { investigados, e sim garantir que os corruptos fiquem longe do } \\
\text { alcance de futuras operações, com alterações na legislação que } \\
\text { dificultassem o combate à ladroagem. Esse alerta tem sido feito por } \\
\text { integrantes da força-tarefa da Lava Jato e pelo juiz Sergio Moro há } \\
\text { muito tempo" }\end{array}$ & \\
\hline $\begin{array}{l}\text { SD15: "dado o clima de conspiração contra a Lava Jato que } \\
\text { predomina em Brasília, a sociedade vai precisar ficar bastante }\end{array}$ & \multirow{2}{*}{$\begin{array}{l}\text { E08: A Câmara e o } \\
\text { combate à corrupção }\end{array}$} \\
\hline $\begin{array}{l}\text { SD16: "A intenção de, por meio da atividade legislativa, minar a } \\
\text { Lava Jato e outras operações de combate aos crimes de agentes } \\
\text { públicos ficou evidente nas gravações de conversas feitas pelo ex- } \\
\text { diretor da Transpetro Sérgio Machado" }\end{array}$ & \\
\hline $\begin{array}{l}\text { SD17: "O que não se pode admitir é qualquer "operação abafa" } \\
\text { justificada por uma potencial instabilidade no governo" }\end{array}$ & E09: Temer e o de-lator \\
\hline
\end{tabular}

Fonte: Elaboração Própria.

\section{FD2: PT, o inimigo número 1}

Os editoriais tratam o Partido dos Trabalhadores, seus representantes e o governo federal como protagonistas do esquema de corrupção investigado pela LJ. Como tal, ícones do PT e aliados próximos são apontados como nomes antagônicos à Operação, apoiando a imagem negativa do partido que estaria trabalhando pela perpetuação da corrupção. 
Tabela 2 - FD2

\begin{tabular}{|c|c|}
\hline Sequência Discursiva & Editorial \\
\hline $\begin{array}{l}\text { SD18: "Se confirmadas, as informações podem representar o fim da } \\
\text { linha para a presidente Dilma e para o expresidente } \\
\text { Lula, pois nenhuma informação dada até o momento pelos } \\
\text { investigados ou presos da Lava Jato implicava o Palácio do Planalto } \\
\text { de forma tão explícita" }\end{array}$ & \multirow[t]{2}{*}{$\begin{array}{l}\text { E01: Acusações } \\
\quad \text { explosivas }\end{array}$} \\
\hline $\begin{array}{l}\text { SD19: "salta aos olhos a velocidade com que Delcídio passou de líder } \\
\text { do governo no Senado a pessoa desacreditada" }\end{array}$ & \\
\hline $\begin{array}{l}\text { SD20: "A divulgação - que não pode em hipótese alguma ser } \\
\text { confundida com "vazamento", expressão que o petismo vem usando } \\
\text { na tentativa de criminalizar a difusão dos áudios - foi feita seguindo } \\
\text { cuidados como o de não expor a intimidade dos investigados" }\end{array}$ & $\begin{array}{l}\text { E02: A lei está do lado } \\
\text { de Moro }\end{array}$ \\
\hline $\begin{array}{l}\text { SD22: "O novo ministro da Justiça ataca as delações premiadas da } \\
\text { Lava Jato e ameaça trocar toda uma equipe caso suspeite de } \\
\text { vazamentos. Será esse o "pulso firme" que Lula desejava? }\end{array}$ & \multirow{4}{*}{$\begin{array}{l}\text { E03: Aragão parte para } \\
\text { o ataque }\end{array}$} \\
\hline $\begin{array}{l}\text { SD23: "Qual seria a melhor estratégia para um governo acuado pela } \\
\text { Operação Lava Jato e interessado em jogar água na fervura das } \\
\text { investigações que chegaram ao centro do poder petista?" }\end{array}$ & \\
\hline $\begin{array}{l}\text { SD24: "uma das convicções mais arraigadas do petismo é a de que } \\
\text { os órgãos de Estado estão a serviço do partido" }\end{array}$ & \\
\hline $\begin{array}{l}\text { SD25: "graças à pressão do ex-presidente Lula, para quem era } \\
\text { obrigação de Cardozo domesticar a Polícia Federal para que a Lava } \\
\text { Jato não incomodasse o chefão petista e seus familiares" }\end{array}$ & \\
\hline $\begin{array}{l}\text { SD26: “...mas não teriam uma ligação pelo menos indireta, já que a } \\
\text { ida de Lula para a Casa Civil seria o meio de escapar dessa } \\
\text { mesmíssima investigação, como ficou provado pelo conteúdo dessas } \\
\text { e de outras ligações?" }\end{array}$ & \multirow{3}{*}{$\begin{array}{l}\text { E04: Vale tudo para } \\
\text { blindar Lula }\end{array}$} \\
\hline $\begin{array}{l}\text { SD27: "mais uma vez a máquina estatal está sendo colocada a } \\
\text { serviço de Lula" }\end{array}$ & \\
\hline $\begin{array}{l}\text { SD28: "têm como principal objetivo protelar indefinidamente a } \\
\text { constatação definitiva de que houve desvio de finalidade na tentativa } \\
\text { de levar Lula para a Casa Civil" }\end{array}$ & \\
\hline $\begin{array}{l}\text { SD 29: "estrutura do governo foi colocada, de uma ou outra forma, a } \\
\text { serviço do projeto petista" }\end{array}$ & \multirow[b]{2}{*}{$\begin{array}{l}\text { E10: A prisão de Paulo } \\
\text { Bernardo }\end{array}$} \\
\hline $\begin{array}{l}\text { SD 30: "Bernardo não é o primeiro ex-Ministro petista preso em } \\
\text { decorrência das investigações iniciadas com a Lava Jato. Mas José } \\
\text { Dirceu já estava fora do governo quando a fonte do mensalão secou e } \\
\text { o PT resolveu buscar outros meios de abastecer seus cofres. Ele }\end{array}$ & \\
\hline
\end{tabular}


representa, podemos dizer, a dimensão "partidária" do esquema. Já a investigação no âmbito daqueles que operavam de dentro do governo havia pego, no máximo, diretores e gerentes de estatais; quando surgem denúncias, acusações e indícios que envolvem até mesmo alguém que agia na qualidade de ministro de Estado, a situação muda de patamar"

Fonte: Elaboração Própria.

\section{FD3: A competência de Sérgio Moro}

O juiz federal Sérgio Moro, que conduz a Operação de Curitiba, adquiriu destaque como figura capaz de promover o combate à corrupção. Nos editoriais da GP, o magistrado é tratado com admiração e respeito, tendo, inclusive, textos dedicados à sua defesa pessoal, em contraposição a imagem do ex-presidente Lula. Assim, a GP constrói uma imagem positiva do juiz que circunda noções de honestidade, competência, lisura, coragem e heroísmo.

Tabela 3 - FD3

\begin{tabular}{|c|c|}
\hline Sequência Discursiva & Editorial \\
\hline $\begin{array}{l}\text { SD31: "Sergio Moro agiu estritamente dentro de suas prerrogativas } \\
\text { e do que prescreve o processo penal ao divulgar o conteúdo das } \\
\text { gravações de Lula" }\end{array}$ & \multirow[t]{4}{*}{$\begin{array}{l}\text { E02: A lei está do lado } \\
\text { de Moro }\end{array}$} \\
\hline $\begin{array}{l}\text { SD 32: "desmoralizar o juiz federal Sergio Moro já era uma } \\
\text { estratégia dos investigados da Lava Jato havia um bom tempo" }\end{array}$ & \\
\hline $\begin{array}{l}\text { SD33: "O que uns chamam de oportunismo nós chamaríamos de } \\
\text { coragem. Impossível saber a intenção do magistrado, mas, se } \\
\text { realmente Moro agiu guiado pelo senso de oportunidade, só podemos } \\
\text { dar-lhe os parabéns. Dentro da legalidade, tomar uma atitude como } \\
\text { a da quarta-feira é mérito" }\end{array}$ & \\
\hline $\begin{array}{l}\text { SD34: "Moro arriscou todas as fichas ao fazer o que fez? É possível. } \\
\text { Mas agiu consciente da legalidade de sua decisão. O Brasil } \\
\text { agradece." }\end{array}$ & \\
\hline $\begin{array}{l}\text { SD35: "Estamos convencidos da legalidade das ações do juiz } \\
\text { federal, e por isso só nos resta esperar que o ministro, ao fim, tome a } \\
\text { decisão correta e reconheça a lisura com que Moro tem conduzido } \\
\text { a Lava Jato." }\end{array}$ & $\begin{array}{l}\text { E04: Vale tudo para } \\
\text { blindar Lula }\end{array}$ \\
\hline $\begin{array}{l}\text { SD36: "Sergio Moro, cuja caneta foi a principal responsável por ter } \\
\text { mostrado o lado avesso da prática política nacional, que não } \\
\text { poupou os maiores notáveis do poder encrustados no governo e nas } \\
\text { grandes empreiteiras cúmplices. Bom lembrar: até agora, menos de } \\
\text { 4\% das decisões de Moro foram reformadas por instâncias superiores" }\end{array}$ & $\begin{array}{l}\text { E05: Proteção } \\
\text { incondicional à Lava } \\
\text { Jato }\end{array}$ \\
\hline
\end{tabular}

Fonte: Elaboração Própria.

FD4: A Operação legítima e defensável 
A defesa da Lava Jato é clara: a GP acusa quem investe contra a Operação, reafirma a relevância da investigação para o país e sentencia: quem está contra a Lava Jato está a favor da corrupção e da impunidade. Para a GP, o apoio popular é unânime. Assim, a imagem da Operação é positiva e relativa a noções de heroísmo e revolução.

Tabela 4 - FD4

\begin{tabular}{|l|l|}
\hline \multicolumn{1}{|c|}{ Sequência Discursiva } & Editorial \\
\hline $\begin{array}{l}\text { SD37: “As evidências parecem comprovar, a cada dia, que a Lava Jato } \\
\text { ainda tem muito a fazer. O trabalho de limpeza ética, ao que tudo indica, } \\
\text { está longe de ser concluído" }\end{array}$ & $\begin{array}{c}\text { E05: Proteção } \\
\text { incondicional à Lava Jato }\end{array}$ \\
\hline $\begin{array}{l}\text { SD38: "Vem daí o risco de esvaziamento da operação já que } \\
\text { popular e politicamente se tornou completamente inviável investir } \\
\text { frontalmente contra ela" }\end{array}$ & \\
\hline $\begin{array}{l}\text { SD39: “...todas as tentativas de interferência saíram fracassadas e com um } \\
\text { alto preço pago por boa parte dos envolvidos" }\end{array}$ & E06: Contra a corrupção \\
\hline $\begin{array}{l}\text { SD40: “A Operação Lava Jato e os efeitos dela decorrentes precisam ser } \\
\text { encarados pelos parlamentares da mesma forma como o são pela } \\
\text { sociedade: um momento de ruptura que abre a oportunidade para a } \\
\text { transformação do ambiente político brasileiro" }\end{array}$ & \\
\hline $\begin{array}{l}\text { SD41: "Saber que o trabalho exemplar realizado no Paraná encontra } \\
\text { ecos pelo país é um conforto - a não ser, claro, para quem contava com a } \\
\text { impunidade" }\end{array}$ & $\begin{array}{l}\text { E10: A prisão de Paulo } \\
\text { Bernardo }\end{array}$ \\
\hline
\end{tabular}

Fonte: Elaboração Própria.

\section{FD5: População deve agir e reagir}

Para evitar obstáculos (alarmados em FD1) que impeçam o sucesso da Lava Jato no combate a crimes de corrupção e na instalação de um novo ambiente político, a GP orienta a população permanecer vigilante e atuante, o que reitera os aspectos positivos que compõem a imagem pública da LJ.

\section{Tabela 5 - FD4}

\begin{tabular}{|c|c|}
\hline Sequência Discursiva & Editorial \\
\hline $\begin{array}{l}\text { SD42: "Se Aragão estiver realmente disposto a minar a Lava Jato, a } \\
\text { sociedade precisa reagir com a mesma força que demonstrou após a } \\
\text { tentativa de levar Lula para o ministério" }\end{array}$ & $\begin{array}{l}\text { E03: Aragão parte para } \\
\text { o ataque }\end{array}$ \\
\hline $\begin{array}{l}\text { SD43: "Essa oportunidade precisar ser aproveitada. E a sociedade } \\
\text { pode ser a indutora desse processo de mudança, se, da mesma } \\
\text { forma que vem demonstrando seu apoio à Lava Jato, encampar uma } \\
\text { mobilização mais ampla para aprovar esses projetos contra a } \\
\text { corrupção. }\end{array}$ & $\begin{array}{l}\text { E06: Contra } \\
\text { corrupção }\end{array}$ \\
\hline $\begin{array}{l}\text { SD44: "Este é um controle que só pode ser feito pela população, } \\
\text { para que não aconteça aqui o que houve na Itália. Atenção máxima } \\
\text { aos projetos de lei que lidam com o combate à roubalheira, apoio a }\end{array}$ & $\begin{array}{l}\text { E07: A trama contra a } \\
\text { Lava Jato }\end{array}$ \\
\hline
\end{tabular}


ATHANÁSIO, E.P. Jogo de imagens na página 2: estudo preliminar da Lava Jato nos editoriais da Gazeta do Povo

\begin{tabular}{|l|l|}
\hline $\begin{array}{l}\text { iniciativas como as Dez Medidas Contra a Corrupção e pressão } \\
\text { popular, inclusive nas ruas, são o melhor jeito de impedir que os } \\
\text { corruptos levem a melhor, no curto ou no longo prazo" }\end{array}$ & \\
\cline { 1 - 1 } $\begin{array}{l}\text { SD45: "Dado o clima de conspiração contra a Lava Jato que } \\
\text { predomina em Brasília, a sociedade vai precisar ficar bastante } \\
\text { atenta à tramitação do projeto" }\end{array}$ & \multirow{2}{*}{$\begin{array}{c}\text { E08: A Câmara e o } \\
\text { combate à corrupção }\end{array}$} \\
\cline { 1 - 1 } $\begin{array}{l}\text { SD46: "Por essas razões, é necessária a mais absoluta vigilância } \\
\text { neste momento de criação da comissão especial na Câmara" }\end{array}$ & \\
\cline { 1 - 2 } $\begin{array}{l}\text { SD47:"A mobilização da sociedade para aprovar as Dez Medidas } \\
\text { Contra a Corrupção é uma tarefa que, se levada a cabo, vai } \\
\text { contribuir para transformar o ambiente político" }\end{array}$ & \\
\hline
\end{tabular}

Fonte: Elaboração Própria.

\section{FD6: Temer não deve temer, mas ser firme}

Na transição de governo, o descrédito do PT se converte em voto de confiança a gestão Temer, então vice-presidente da República que na ocasião buscava a concretização do processo de impeachment contra Dilma para assumir o executivo federal. Os editoriais dão uma chance ao PMDB e cobram postura firme do novo líder, a fim de garantir o êxito da Lava Jato. Neste ponto, nota-se que, apesar de defender a LJ e atacar o PT por conta da intenção de combater a corrupção e, assim, defender o interesse público, no caso do então vice-presidente, Michel Temer, a GP foi mais tolerante e apoiou o substituto de Dilma, construindo a imagem de uma solução competente para o estado crítico vivido pelo país no período analisado.

\section{Tabela 6 - FD6}

\begin{tabular}{|l|c|}
\hline \multicolumn{1}{|c|}{ Sequência Discursiva } & Editorial \\
\hline $\begin{array}{l}\text { SD48: "Mas suas declarações não têm sido suficientes para aplacar a } \\
\text { desconfiança de que o que mais desejam os investigados da cúpula de } \\
\text { seu partido é manobrar para obstruir ou reduzir os danos que ela ainda } \\
\text { pode causar. Por isso, o presidente precisa ser mais enfático. Temer } \\
\text { tem que estar atento para assegurar que as garantias que deu sejam } \\
\text { cumpridas e, até mesmo, se necessário, atuar para a blindagem do } \\
\text { trabalho dos envolvidos na operação." }\end{array}$ & $\begin{array}{c}\text { E05: Proteção } \\
\text { incondicional à Lava } \\
\text { Jato }\end{array}$ \\
\hline $\begin{array}{l}\text { SD49: "toda a atenção de Temer é necessária para que, além da } \\
\text { "salvação nacional" de que falou em seu discurso de posse, permaneça } \\
\text { assegurada a continuidade da atuação implacável da Lava Jato" }\end{array}$ & \\
\hline $\begin{array}{l}\text { SD50: "Apesar de declarar apoio público à Lava Jato, o governo não } \\
\text { deu a mínima atenção até agora a esse relevante conjunto de } \\
\text { medidas" }\end{array}$ & $\begin{array}{l}\text { E08: A Câmara e o } \\
\text { combate à corrupção }\end{array}$ \\
\hline $\begin{array}{l}\text { SD51: "Por isso, se Temer não quiser repetir Dilma, interrompendo } \\
\text { ainda no início um esforço que pode ser fundamental para o país, }\end{array}$ & E09: Temer e o de-lator \\
\hline
\end{tabular}


terá de sanear sua equipe, livrando-a de quaisquer elementos suspeitos"

Fonte: Elaboração Própria.

\section{CONSIDERAÇÕES FINAIS}

A Lava Jato é a uma oportunidade rara de mudança do ambiente político brasileiro. É o que afirmam os editorias da Gazeta do Povo, no período de março a junho de 2016. O corpus analisado revela que o posicionamento editorial do jornal sequer questiona qualquer iniciativa da equipe de investigação da operação. Ao contrário, no momento de maior impasse vivido pelo juiz Sérgio Moro, quando acusado de abuso de autoridade pelo vazamento das gravações de conversas entre Lula e Dilma, o periódico parabenizou a conduta do juiz e, em outro momento, se revelou orgulhoso da expressividade paranaense frente à luta nacional contra a corrupção.

A $\mathrm{AD}$ demonstra que a temática mais recorrente é a ênfase na existência de uma ofensiva sistemática, oriunda de diversos grupos políticos e concentrada no PT e no poder legislativo, com intuito de impedir o avanço da investigação. Aliado a essa mesma ideia, o segundo ponto mais presente reside na crítica constante ao PT e seus aliados. O PT aparece como responsável por tamanha e inédita corrupção, o mais prejudicado e o principal articulador contrário à punição, aquele que se vale de qualquer instrumento para burlar a lei e perpetuar a corrupção.

Moro e a Lava Jato aparecem como figuras respeitáveis e isentas de qualquer equívoco. A população é citada como peça fundamental para monitoramento, pressão e mobilização. No contexto pós-impeachment, Temer se torna mais presente nos textos, sendo reivindicado para garantir, na condição de presidente, o triunfo da LJ e consequente fim do "velho modo de se fazer política".

Conclui-se, portanto, que a linha editorial traduzida nos editoriais da Gazeta do Povo colabora para a construção de uma imagem totalmente positiva da operação Lava Jato, apresentando-a sob um olhar otimista e não apenas apoiador, mas também defensivo, o que dialoga com o próprio discurso de autolegitimação do Jornalismo, que reivindica para si o papel social de defesa do interesse público e fiscalização do poder político. Logo, ao abordar a temática da corrupção, é coerente que o jornal assuma essa postura - contudo, nota-se, nesta análise, que o faz com pouca problematização, estabelecendo um ambiente de oposição quase 
ATHANÁSIO, E.P. Jogo de imagens na página 2: estudo preliminar da Lava Jato nos editoriais da Gazeta do Povo

maniqueísta entre PT (acusados, culpados) e inocentes (personalidades responsáveis pela investigação).

Contudo, um achado importante diz respeito à variável "grupo acusado", já que se pode concluir que a Gazeta do Povo é mais sutil nas avaliações sobre Temer, enquanto foi intolerante com o grupo petista durante períodos semelhantes, protagonizados por críticas similares. Logo, a Lava Jato tem uma identidade construída a partir da negação do PT, mas também foi construída a favor do governo interino de Temer.

Assim, o jornal age como ator político, interferindo no debate público, propondo determinadas posições e saídas para o cenário político - o que ficou evidenciado durante o processo de impeachment, quando a GP sugeriu veementemente a saída de Dilma. Deste modo, ao tratar da LJ em seus editoriais, a linha editorial adotada promove uma negativa do PT, em um processo de desconstrução da imagem pública daqueles que compõem o grupo, mas, em contrapartida, ao enaltecer a Operação Lava Jato e concomitante advogar a favor do impeachment, o jornal constrói imagens positivas daqueles que representam a Força-Tarefa, mas também acaba atuando em favor de outros atores políticos, muito embora não possam ser exemplos de anticorrupção - o que ficou claro quando analisada a imagem de Temer. Ao criminalizar Dilma e o PT e enaltecer o governo Temer, a GP atuou politicamente.

\section{REFERÊNCIAS}

AVRITZER, L. 2016. Impasses da democracia no Brasil. Rio de Janeiro: Editora Civilização Brasileira, 154 pp.

BARROS FILHO, C. 1995. Ética na Comunicação: da informação ao receptor. São Paulo: Moderna.

BENETTI, M. 2008. O Jornalismo como gênero discursivo. Revista Galáxia, São Paulo, n. 15, p. 13-28, jun. 2008.

BIROLI, F; MIGUEL, L. F. 2012. Orgulho e Preconceito: a "objetividade" como mediadora entre o Jornalismo e seu público. Revista Opinião Pública, Campinas, vol.18, nº1, p. 22-43.

BREED, W. 1955. Reedição de "Social Forces" (Vol.33, Fall,). Social Control in the Newsroom: A Functional Analysis. Direitos do autor: Social Forces.

CAPPELlE, M. C. A.; MELO, M. C. O. L.; GONÇALVES, C. 2003. A. Análise de conteúdo e análise de discurso nas ciências sociais. Organizações Rurais \& Agroindustriais, v. 5, n. 1, art. 6, p. 0-0. 
CARVALHO, G. 2013. Diretrizes para a Análise de Discurso em Jornalismo. Revista Uninter de Comunicação, ano 1, n. 1.

CHARAUDEAU, P. 2004. Gênero de discurso. In: CHARAUDEAU, P; MAINGUENEAU, D. (Org.). Dicionário de análise do discurso. São Paulo: Contexto.

EILDERS, C. 1999. Synchronization of Issue Agendas in News and Editorials of the Prestige Press in Germany. In: Communications. Volume 24, Issue 3, Pages 301- 328.

ENTMAN, R.M. 1993. 'Framing: Toward Clarification of Fractured Paradigm'. Journal of Communication, 43 (4), p. 51- 58.

GALICIA, J. 2010. Posicionamiento. In Treinta claves para entender el poder. México, Piso 15.

GOMES, W. 2004. A política de imagem. In: Transformações da política na era da comunicação de massa. São Paulo: Paulus. Cap 06.

MAIA, R. C. M. 2008. Deliberação e Mídia. In: Rousiley C.M. Maia. (Org.). Mídia e Deliberação. 1ed., Rio de Janeiro: Editora FGV, v. 1, p. 93-119

MARQUES DE MELO, J. 2003. Jornalismo opinativo: gêneros opinativos no Jornalismo brasileiro. 3. ed. Campos de Jordão, RJ: Editora Mantiqueira.

McCOMBS, M. 2009. Setting the agenda. The mass media and public opinion. PolityPress, 2004. (Edição brasileira pela Vozes, 2009. Teoria da agenda).

MONT'ALVERNE, C. ; MARQUES, F. P. J. A. 2015. A opinião da empresa no Jornalismo brasileiro: um estudo sobre a função e a influência política dos editoriais. Estudos em Jornalismo e Mídia (UFSC), v. 12, p. 121-137.

PINHEIRO, Y. 2013. O discurso do jornal O Estado de S. Paulo sobre o Mercosul. Fortaleza.

RINK, E. M.2015. Verbete "Mediated Deliberation", In: MAZZOLENI, G; BARNHURST, K; IKEDA, K; MAIA, R; WESSLER, H. (Org.). The International Encyclopedia of Political Communication. 1ed.London: Wiley-Blackwell.

TUCHMAN, G. 1972. Reedição de "American Journal of Sociology" (Vol. 77, № 2). Objectivity as Strategic Ritual: Na Examinacion of Newsmen's Notions of Objectivity. Direitos do autor: The University of Chicago.

TUCHMAN, G. 1976. Reedição de "Journal of Communication” (Vol. 26, N 4). Telling Stories. Direitos do autor: Oxford University Press.

WEBER, M. H. 2004. Imagem Pública. In: RUBIM, Antônio. Comunicação e Política, conceitos e abordagens. Salvador: Editora UFBA. p. 259-308. 